\title{
ASO Visual Abstract: Inflammatory Breast Cancer at the Extremes of Age
}

Taiwo Adesoye, MD, MPH ${ }^{1}$, Oluwatowo Babayemi, $\mathrm{MPH}^{2}$, Lauren M. Postlewait, $\mathrm{MD}^{3}$, Sarah M. DeSnyder, MD, FACS ${ }^{1,4}$, Susie X. Sun, MD ${ }^{1,4}$, Wendy A. Woodward, MD, PhD $^{4,5}$, Naoto T. Ueno, MD, PhD, FACP ${ }^{4,6}$, Kelly Hunt, MD $^{1}$, Anthony Lucci, MD, FACS ${ }^{1,4}$, and Mediget Teshome, MD, MPH, FACS ${ }^{1,4}$ (D)

${ }^{1}$ Department of Breast Surgical Oncology, The University of Texas MD Anderson Cancer Center, Houston, TX; ${ }^{2}$ Department of Health Services Research, Division of Cancer Prevention and Population Sciences, The University of Texas MD Anderson Cancer Center, Houston, TX; ${ }^{3}$ Division of Surgical Oncology, Department of Surgery, Emory University, Atlanta, GA; ${ }^{4}$ Morgan Welch Inflammatory Breast Cancer Research Program and Clinic, The University of Texas MD Anderson Cancer Center, Houston, TX; ${ }^{5}$ Department of Radiation Oncology, The University of Texas MD Anderson Cancer Center, Houston, TX; ${ }^{6}$ Department of Breast Medical Oncology, The University of Texas MD Anderson Cancer Center, Houston, TX

Inflammatory breast cancer (IBC) is a rare breast malignancy with poor outcomes. Our study (https://doi.org/ 10.1245/s10434-021-10453-9) identified no significant age-related differences in presentation, treatment, or outcomes that support de-escalation of care in elderly patients with IBC.

\section{Inflammatory Breast Cancer At Extremes Of Age}

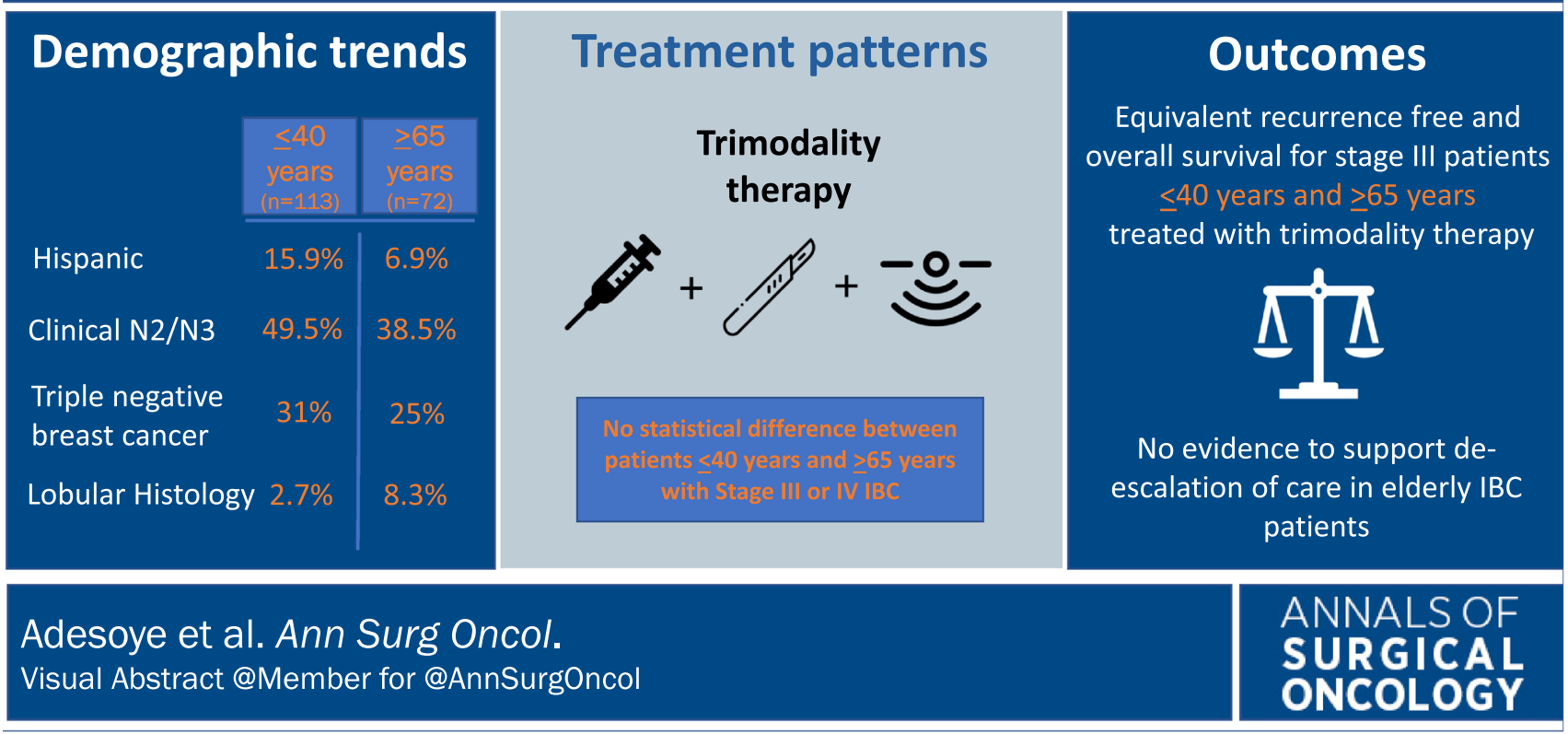

(C) Society of Surgical Oncology 2021

Published Online: 6 November 2021

Publisher's Note Springer Nature remains neutral with regard to

M. Teshome, MD, MPH, FACS

e-mail: MTeshome@mdanderson.org 